\title{
TEKNIK INVENTARISASI GUNA LAHAN DENGAN PERANGKAT DRONE
}

\author{
Ir. Nico D Djajasinga, M.Sc \\ Dosen STTD \\ Jl. Raya Setu No. 89, Cibuntu, \\ Cibitung, Bekasi 17520 \\ Telp./Fax : (021) 8254640
}

\author{
Utut W. M.Sc \\ Dosen STTD \\ Jl. Raya Setu No. 89, Cibuntu, \\ Cibitung, Bekasi 17520 \\ Telp./Fax : (021) 8254640
}

\author{
Ir. J R C Hosang \\ Dosen STTD \\ Jl. Raya Setu No. 89, Cibuntu, \\ Cibitung, Bekasi 17520 \\ Telp./Fax : (021) 8254640
}

\author{
Feri Subekti, MT \\ Dosen STTD \\ J1. Raya Setu No. 89, Cibuntu, \\ Cibitung, Bekasi 17520 \\ Telp./Fax : (021) 8254640
}

\author{
Eka Arista, M.Sc \\ Dosen STTD \\ Jl. Raya Setu No. 89, Cibuntu, \\ Cibitung, Bekasi 17520 \\ Telp./Fax : (021) 8254640
}

\begin{abstract}
Land use is the human activity and in relation to the land, which is usually not directly visible from the image. Land use do not have the correct definition on the whole different context. While the land cover is a picture of the vegetation and artificial constructs that cover the surface of the land. Such construction is a construction that is visible from a remote sensing image.

One of these is the use of remote sensing Geographical Information Systems. Imagery obtained through remote sensing is a basic data input or subsequently processed and presented by the Geographic Information System. The position of the data from remote sensing image can be corrected in a Geographic Information System. Thus, the integration between data Remote Sensing with Geographical Information Systems will obtain optimum information as utilization data region.

Mechanical Inventory by using drone to take pictures of a few points, they can determine the level of alignment with the more accurate maps, meaning that the use of drones for accurate results, you have to do more than one recording point to that region in the survey

It can be seen that the construction site of the railway track between the topographic map and recording results demonstrate the suitability drone same point.
\end{abstract}

\footnotetext{
ABSTRAKSI

Penggunaan lahan merupakan aktivitas manusia pada dan dalam kaitannya dengan lahan, yang biasanya tidak secara langsung tampak dari citra. Penggunaan lahan tidak memiliki satu definisi yang benar - benar tepat di dalam keseluruhan konteks yang berbeda. Sedangkan penutup lahan merupakan gambaran kostruksi vegetasi dan buatan yang menutup permukaan lahan. Konstruksi tersebut merupakan konstruksi yang tampak dari sebuah citra penginderaan jauh.

Salah satu pemanfaatan penginderaan jauh tersebut adalah Sistem Informasi Geografi. Citra yang diperoleh melalui penginderaan jauh merupakan data dasar atau input yang selanjutnya diolah dan disajikan oleh Sistem Informasi Geografi. Posisi data dari citra Penginderaan Jauh dapat dikoreksi kembali dalam Sistem Informasi Geografi. Dengan demikian, integrasi antara data Penginderaan Jauh dengan Sistem Informasi Geografi akan memperoleh informasi yang optimal sebagai data pemanfaatan wilayah.

Teknik inventarisai dengan drone mengambil gambar dari beberapa titik, maka akan didapatkan tingkat kesejajaran dengan peta semakin akurat, artinya penggunaan drone utk memiliki hasil yg akurat harus dilakukan perekaman lebih dr 1 titik terhadap wilayah yg di survey
} 


\section{PENDAHULUAN}

\section{A. Latar Belakang}

Penggunaan lahan merupakan aktivitas manusia pada dan dalam kaitannya dengan lahan, yang biasanya tidak secara langsung tampak dari citra. Penggunaan lahan tidak memiliki satu definisi yang benar - benar tepat di dalam keseluruhan konteks yang berbeda. Sedangkan penutup lahan merupakan gambaran kostruksi vegetasi dan buatan yang menutup permukaan lahan. Konstruksi tersebut merupakan konstruksi yang tampak dari sebuah citra penginderaan jauh.

Salah satu pemanfaatan penginderaan jauh tersebut adalah Sistem Informasi Geografi. Citra yang diperoleh melalui penginderaan jauh merupakan data dasar atau input yang selanjutnya diolah dan disajikan oleh Sistem Informasi Geografi. Posisi data dari citra Penginderaan Jauh dapat dikoreksi kembali dalam Sistem Informasi Geografi. Dengan demikian, integrasi antara data Penginderaan Jauh dengan Sistem Informasi Geografi akan memperoleh informasi yang optimal sebagai data pemanfaatan wilayah.

Sekolah Tinggi Trasnportasi Darat mendapatkan bantuan berupa Pembangunan Laboratorium Outdoor Track Kereta Api sepanjang $120 \mathrm{~km}$. Dalam melakukan pembangunan, maka diperlukan inventarisasi guna lahan untuk mengetahui kemiringan dan ketinggian lahan area Sekolah Tinggi Transportasi Darat guna kesesuaian dengan pembangunan Track KA.

\section{B. Perumusan Masalah}

Berdasarkan uraian di atas, maka dirumuskan masalah yang akan dibahas dalam penelitian ini, yaitu:

1. Bagaimana teknik inventarisasi guna lahan dengan menggunakan drone?

2. Seberapa besar manfaat teknik inventarisasi penggunaan lahan dengan menggunakan drone?

\section{Tujuan Penelitian}

Tujuan dari penelitian ini adalah:

1. Mendesain teknik inventarisasi guna lahan dengan menggunakan drone

2. Memetakan guna lahan STTD untuk pengembangan laboratorium perkeretaapian

\section{Ruang Lingkup Penelitian}


Ruang lingkup merupakan batasan penelitian dalam pelaksanaan pengambilan data dan analisis yang akan dibahas sehingga penelitian yang dihasilkan merumus pada suatu pemecahan masalah dengan optimal. Ruang lingkup dalam penelitian ini adalah:

1. Lokasi penelitian adalah di Sekolah Tinggi Transportasi Darat.

2. Penelitian hanya melihat kesesuaian tata guna lahan dengan pembangunan Track KA

3. Kondisi Operasional Drone

Keterbatasan kemampuan peralatan yang dijelaskan pada kondisi operasional, mengubah skenario awal yaitu membuat peta berdasarkan data rekaman foto udara dan rekaman koordinat yang didapat dari drone. Hal ini tidak dapat dilakukan karena drone tidak dilengkapi dengan GPS sehingga harus mengambil titik koordinat secara manual langsung dilapangan menggunakan peralatan GPS.

\section{TINJAUAN PUSTAKA}

\section{A. Penggunaan Lahan}

Pengertian penggunaan lahan adalah segala campur tangan manusia, baik secara permanen maupun secara siklus terhadap suatu kelompok sumber daya alam dan sumber daya buatan,yang secara keseluruhan disebut lahan, dengan tujuan untuk mencukupi kebutuhan-kebutuhannya baik secara kebendaan maupun spiritual ataupun keduaduanya (Malingreau,1977). Peta penggunaan lahan merupakan salah satu aplikasi data penginderaan jauh yang sangat penting digunakan dalam perencanaan penggunaan lahan dan tata guna lahan. Pemetaan penggunaan lahan suatu daerah merupakan usaha untuk mengumpulkan menganalisa, dan mengklasifikasi data penggunaan lahan suatu daerah yang bersangkutan serta menuangkannya dalam bentuk dengan menggunakan metode tertentu agar peta yang dihasilkan dapat dengan mudah dimengerti, memberikan gambaran yang jelas dan sebenarnya rapi dan bersih (Sandy,I Made,1973). Menurut Fauzi A (1994) daerah pinggiran kota mempunyai kemungkinan lebih banyak untuk berkembang menjadi daerah perkotaan dibandingkan dengan daerah yang jauh dari kota. Perubahan lahan terkait dengan letak suatu lahan dan kemudahannya dijangkau. Aksesibilitas dari suatu lahan terhadap fasilitas perkotaan dianggap memberi keuntungan dengan anggapansemakin mudah dijangkau atau semakin strategis suatu lahan maka permintaan akan lahan meningkat. Sarana dan prasarana perhubungan merupakan media yang sangat penting untuk mengembangkan sektorkehidupan disuatu wilayah. Adanya fasilitas perdagangan dan pendidikan merupakan salah satu indikator kegiatan sosial ekonomi disuatu wilayah. 


\section{B. Inventarisasi Guna Lahan Tanah}

Inventarisasi merupakan suatu sumber daya (lahan) ialah suatu kegiatan mengumpulkan dan memilih data tentang sumber daya bersangkutan dalam jumlah dan bentuk yang memungkinkan memperoleh informasi yang patut dan selanjutnya mengevaluasinya untuk keperluan penggunaan sumberdaya tersebut (disadur dari Cline, 1981). Dokumen informasi yang sudah sejak lama digunakan dan sampai sekarang tetap digunakan secara luas adalah peta tematik dari tiap komponen latah (peta iklim, peta tanah, peta geologi, peta topografi, dsb).

\section{Inventarisasi Guna lahan meliputi :}

- Penatagunaan tanah adalah sama dengan pola pengelolaan tata guna tanah yang meliputi penguasaan, penggunaan dan pemanfaatan tanah yang berwujud konsolidasi pemanfaatan tanah melalui pengaturan kelembagaan yang terkait dengan pemanfaatan tanah sebagai satu kesatuan sistem untuk kepentingan masyarakat secara adil.

- Penggunaan tanah adalah wujud tutupan permukaan bumi baik yang merupakan bentukan alami maupun buatan manusia.

- Pemanfaatan tanah adalah kegiatan untuk mendapatkan nilai tambah tanpa mengubah wujud fisik penggunaan tanahnya.

- Rencana Tata Ruang Wilayah adalah hasil perencanaan tata ruang berdasarkan aspek administratif dan atau aspek fungsional yang telah ditetapkan.

Penatagunaan tanah bertujuan untuk:

a. mengaturpenguasaan, penggunaan dan pemanfaatan tanah bagi berbagai kebutuhan kegiatan pembangunan yang sesuai dengan Rencana Tata Ruang Wilayah;

b. mewujudkan penguasaan, penggunaan dan pemanfaatan tanah agar sesuai dengan arahan fungsi kawasan dalam Rencana Tata Ruang Wilayah;

c. mewujudkan tertib pertanahan yang meliputi penguasaan, penggunaan dan pemanfaatan tanah termasuk pemeliharaan tanah serta pengendalian pemanfaatan tanah;

d. menjamin kepastian hukum untuk menguasai, menggunakan dan memanfaatkan tanah bagi masyarakat yang mempunyai hubungan hukum dengan tanah sesuai dengan Rencana Tata Ruang Wilayah yang telah ditetapkan.

\section{Penginderaan jauh}

Penginderaan jauh ialah ilmu dan seni untuk memperoleh informasi tentang obyek, daerah atau gejala dengan cara menganalisis data yang diperoleh dengan menggunakan 
alat tanpa kontak langsung terhadap obyek, daerah atau gejala yang dikaji (Lillesand dan Kiefer dalam Sutanto, 1986). Di dalam penginderaan jauh,sensor merekam tenaga yang dipantulkan atau dipancarkan oleh obyek permukaan bumi. Rekaman tenaga ini setelah diproses membutuhkan data penginderaan jauh. Data penginderaan jauh dapat berupa data digital atau data numerik untuk dianalisis dengan menggunakan komputer. Ia juga dapat berupa data visual yang pada umumnya dianalisis secara manual. Data visual dibedakan lebih jauh atas data citra dan non-citra. Data citra berupa gambaran yang mirip dengan wujud aslinya atau paling tidak berupa gambar abplanimetrik. Data non-citra pada umumnya berupa garis atau grafik sebagai contoh data non-citra ialah grafik yang mencerminkan beda suhu yang direkam disepanjang daerah penginderaan.

Manfaat penginderaan jauh di bidang penggunaan lahan adalah sebagai berikut:

\section{Pemetaan Penggunaan Lahan}

Inventarisasi penggunaan lahan penting dilakukan untuk mengetahui apakah pemetaan lahan yang dilakukan oleh aktivitas manusia sesuai dengan potensi ataupun daya dukungnya. Penggunaan lahan yang sesuai memperoleh hasil yang baik, tetapi lambat laun hasil yang diperoleh akan menurun sejalan dengan menurunnya potensi dan daya dukung lahan tersebut.

\section{Penentuan Arahan Lahan}

Penentuan batas-batas keserasian sumberdaya air merupakan salah satu aspek utama dalam pengelolaan Daerah Aliran Sungai (DAS) sebagai bahan pertimbangan penyusunan konsep tata ruang kawasan.Ketetapan penataan tata ruang didasarkan pada tiga faktor yaitu lereng lapangan, jenis tanah menurut kepekaannya terhadap erosi dan intensitas hujan harian wilayah yang bersangkutan.

\section{Penggunaan Lahan Pertanian}

Dalam usaha memelihara konsistensi penggunaan lahan sebagai areal pertanian maka diperlukan suatu sistem monitoring yang mampu mengamati, menganalisa, menyajikan serta membuat model-model keputusan sehingga aktifitas pertanian yang berkelanjutan tetap terjaga.

\section{Penggunaan Lahan Kehutanan}

Bidang kehutanan berkenaan dengan pengelolaan hutan untuk kayu termasuk perencanaan pengambilan hasil kayu, pemantauan penebangan dan penghutanan kembali, pengelolaan dan pencacahan margasatwa, inventarisasi dan pemantauan sumber daya hutan, rekreasi, dan pengawasan kebakaran.

\section{Penggunaan Lahan Perkebunan}


Manfaat dari menggunakan RS dan teknologi GIS tergantung pada tingkat keberhasilan penerapannya untuk menyelesaikan masalah spasial.Secara umum, manfaat ini dapat dibagi menjadi empat kategori seperti efisiensi ilmiah, teknologi, metodologi, dan ekonomi. Efisiensi ilmiah penginderaan jauh data juga termasuk memperoleh fakta-fakta baru untuk menguatkan dan klarifikasi sebelumnya dikenal kuantitatif, data kualitatif yang dipelajari.

\section{Sumber Tenaga}

Dalam penginderaan jauh harus ada sumber tenaga, baik sumber tenaga alamiah maupun sumber tenaga buatan. Tenaga ini mengenai obyek dipermukaan bumi kemudian dipantulkan ke sensor. Ia juga dapat berupa tenaga dari obyek yang dipancarkan ke sensor. Jumlah tenaga matahari yang mencapai bumi dipengaruhi oleh waktu (jam,musim), lokasi, dan kondisi cuaca.. Pada musim saat matahari berada tegak lurus disuatu tempat, jumlah tenaga lebih besar bila dibandingkan dengan musim dengan musim lain saat matahari kedudukannya condong terhadap tempat tersebut. Disamping itu, jumlah tenaga yang diterima juga dipengaruhi oleh letak tempat dipermukaan bumi. Tempat-tempat di ekuator menerima tenaga lebih banyak bila dibandingkan dengan terhadap tempat-tempat di lintang tinggi. Untuk waktu dan letak yang sama, jumlah sinar matahari yang mencapai bumi dapat berbeda dilihat dari kondisi cuaca yang berbeda.

\section{METODOLOGI PENELITIAN}

\section{A. Lokasi dan Waktu Penelitian}

1. Lokasi

Lokasi penelitian ini berada pada lahan di daerah sekitar Sekolah Tinggi Transportasi Darat (STTD), dimana merupakan kawasan campuran yang peruntukannya untuk perumahan, sekolah, industry dan persawahan. Secara administrative pemerintahan terletak di desa Cibuntu, Kecamatan Setu, Kabupaten Bekasi, Propinsi Jawa Barat.

2. Waktu Penelitian.

Penelitian ini memakan waktu 4 (empat) bulan, sebagai berikut: waktu untuk persiapan dasar 2 minggu, tahap observasi 1 bulan, pengerjaan dan analisis data 2 bulan, dan waktu untuk perbaikan penelitian 2 minggu. 


\section{B. Desain Penelitian}

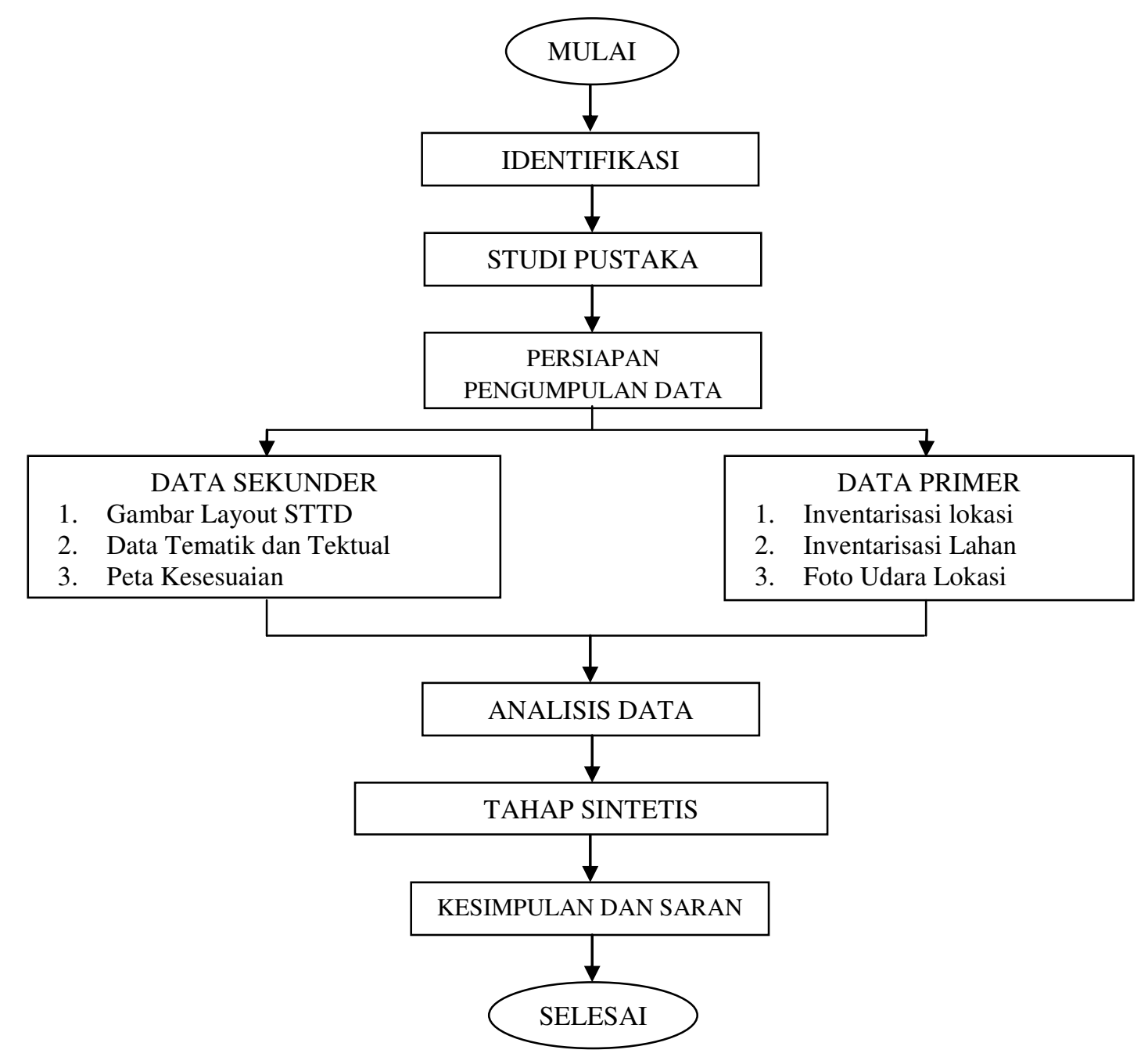

Proses perencanaan Landscape adalah sebagai berikut:

1. Tahap persiapan

Teknik pengumpulan data yang dilakukan ini adalah dengan cara:

a. Langsung mengunjungi lokasi/tempat yang dijadikan penelitian (observasi lapangan) dan mengetahui kondisi tapak

b. Menyiapkan daftar pra inventarisasi data

c. Mengumpulkan informasi dasar

d. Mengkaji data maupun teori baik dari data sekunder maupun primer

e. Membuat gagasan dan tujuan perencanaan

f. Dokumentasi photo

2. Tahap inventarisasi

Di tahap ini harus dilakukan inventaris kondisi lingkungan di STTD agar memudahkan pelaksanaan dan penelitian ini yaitu: 

a. Merumuskan permasalahan
b. Inventarisasi peta kemiringan, peta kontur, dan penggunaan lahan
c. Inventarisasi konsep perencanaan

3. Tahap analisis

Di tahap analisis yang harus dilakukan adalah:

a. Analisis dari peta topografi menggunakan peta kemiringan lahan, peta kemiringan lereng, dan peta penggunaan lahan untuk di overlay menjadi peta kesesuaian lahan

b. Aplikasi analisis menggunakan teori-teori.

4. Tahap sintesis

Tahap yang harus dilakukan adalah:

a. Mengkaji konsep perencanaan yang telah dibuat sebelumnya untuk digunakan pengolahan data selanjutnya

b. Mendapatkan hasil dan data kesesuaian lahan dari teknik overlay

\section{Teknik Pengumpulan Data}

Adapun teknik pengumpulan data yang digunakan dalam penelitian ini terdapat dua proses teknik pengambilan data yaitu data primer dan data sekunder yang dapat dilihat dibawah ini:

1. Data primer

Data yang dapat dilihat dengan melakukan pengamatan dan pencatatan secara sistematis terhadap gejala atau fenomena yang ada pada objek penelitian. Pengumpulan data primer dari penelitian ini dengan cara:
a. Observasi
b. Dokumentasi

2. Data sekunder

Data yang didapat dengan teknik pengumpulan data yang mengacu pada teoritis.
a. Peta kontur
b. Studi literature

\section{Teknik Analisis Data}

Jenis data yang terkumpul dalam penelitian ini adalah data kualitatif. Teknik analisis yang digunakan dalam penelitian adalah Analisis Overlay (kesesuaian Lahan)

\section{ANALISIS}




\section{A. Peta Topografi}

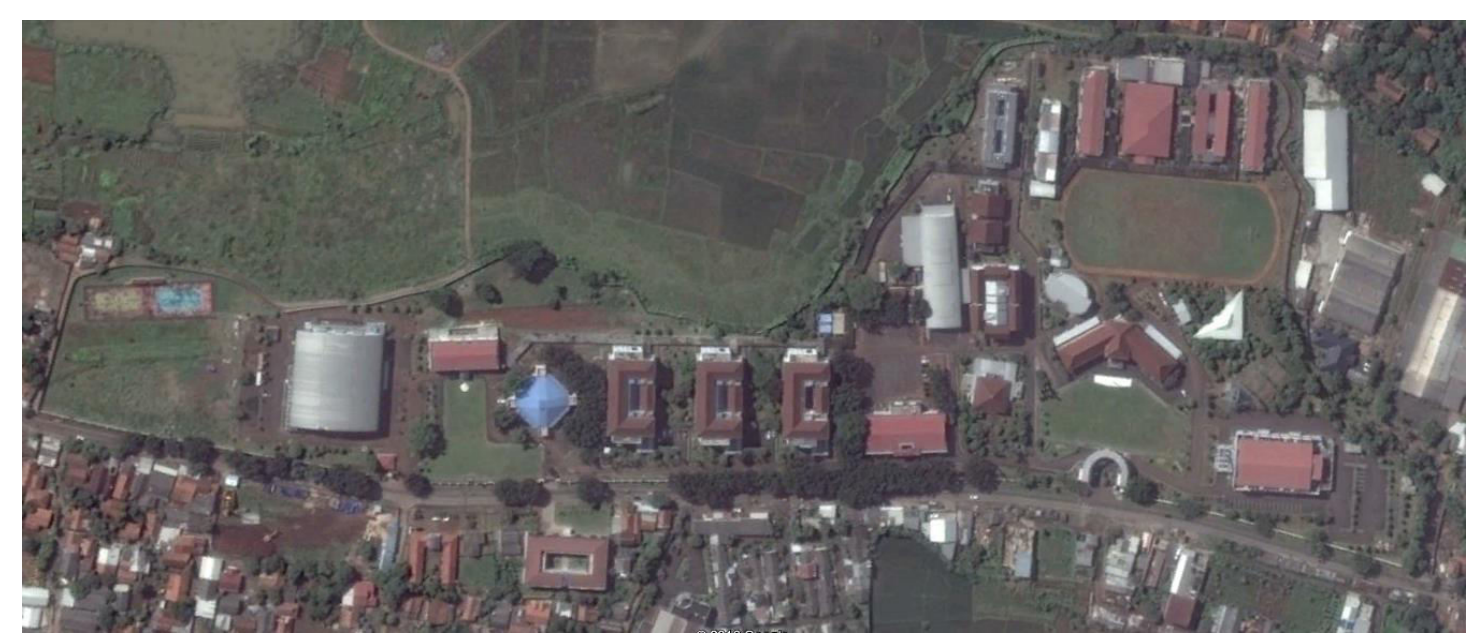

Gambar 4.1 Kenampakan Sekolah Tinggi Transportasi Darat melalui Google earth

Peta topografi seperti pada gambar 4.2 bagian dari area STTD khususnya bagian dari lokasi studi kasus pembangunan track KA di STTD. Peta topografi digunakan untuk mengoverlay hasil dari rekaman inventarisasi dengan drone. Dari Peta diatas dapat kita peroleh koordinat dengan menggunakan GPS secara manual dikarenakan drone yang dipakai dalam penelitian ini hanya mampu menggambarkan rekaman foto dan video dalam inventarisasi guna lahanGambar 4. 2 Peta Topografi

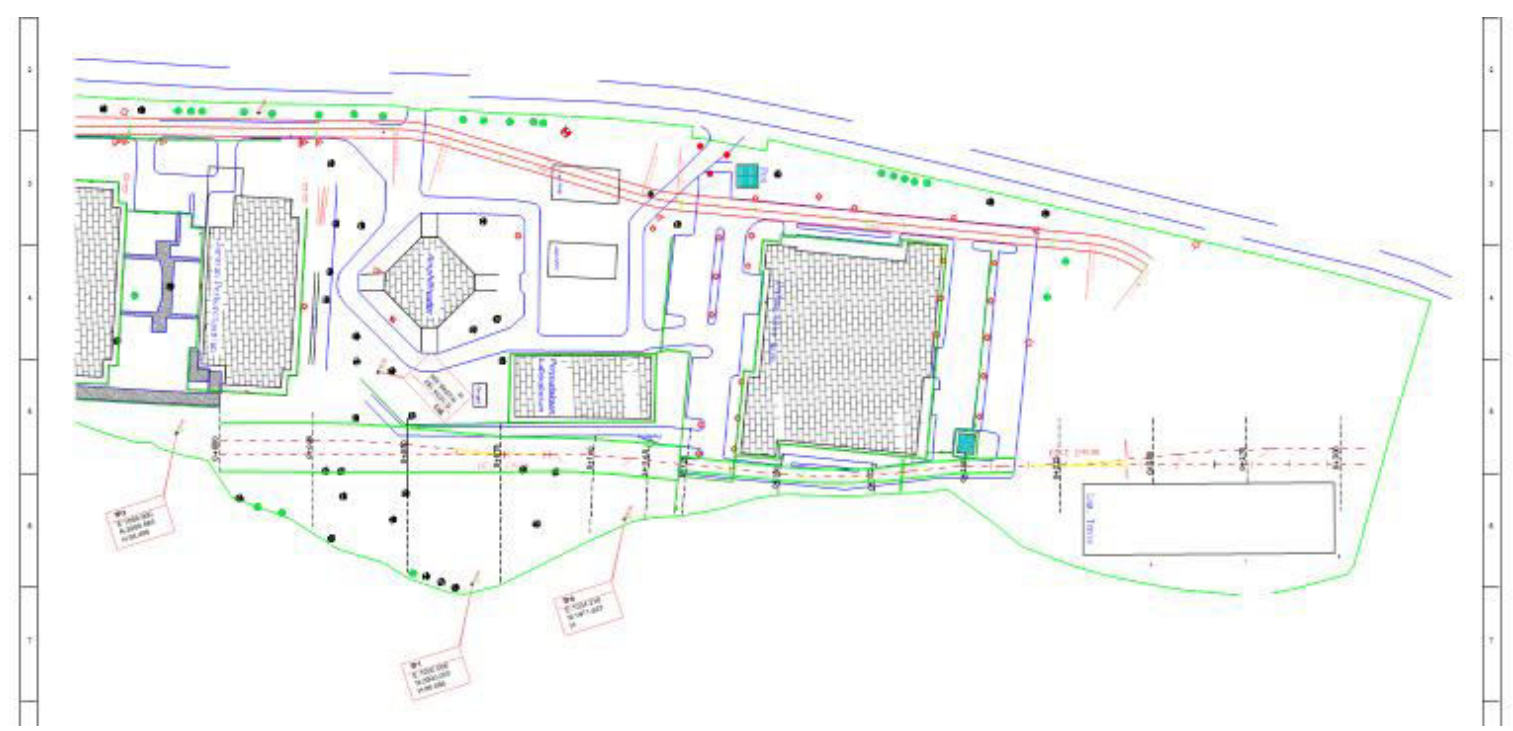


TABEL 4.1 Koordinat pembangunan layout track KA CONVERSION FROM DEGREES INTO DECIMAL

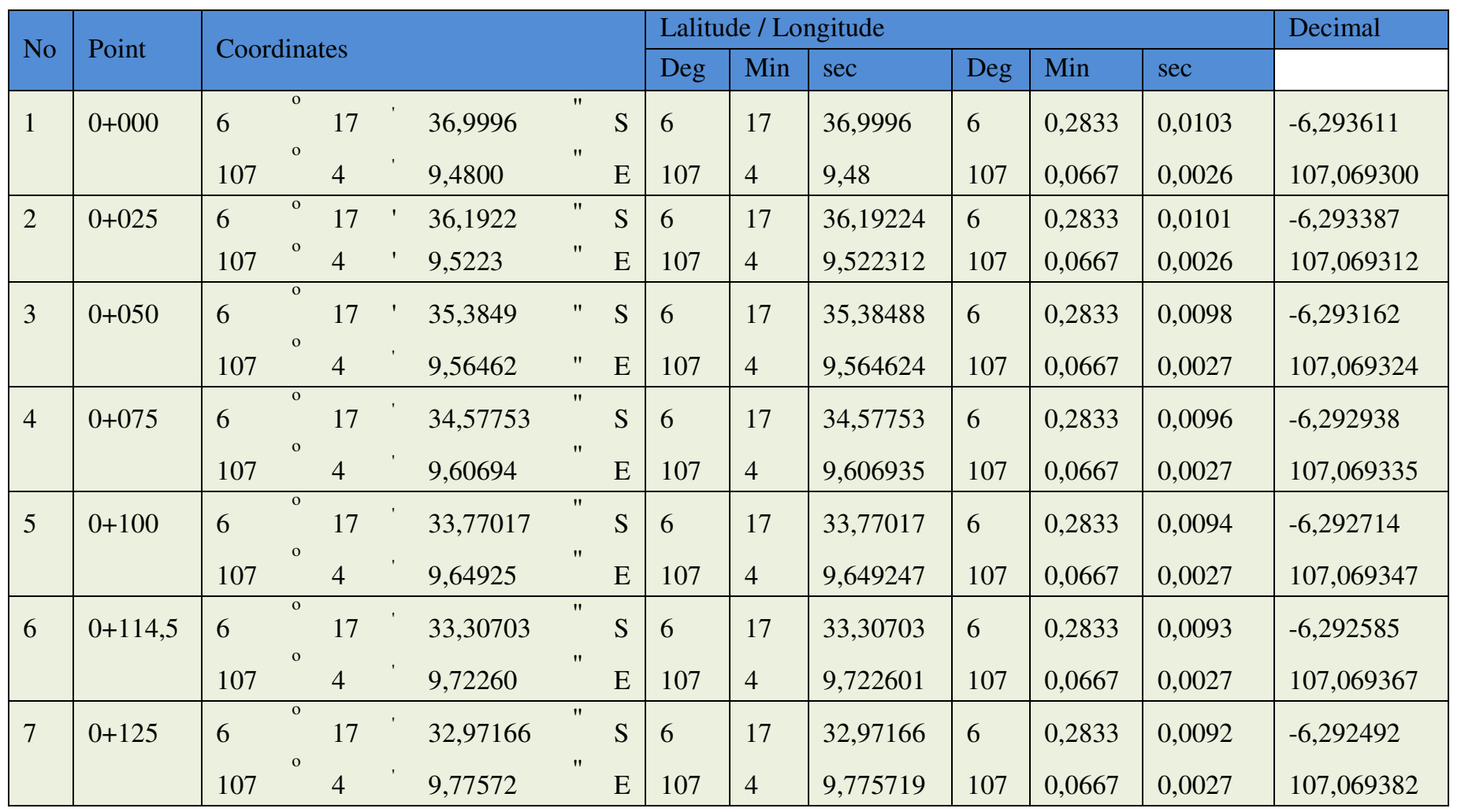

Sumber : survey koordinat, 2016

\section{B. Langkah Penggunaan Drone}

Dari hasil inventarisasi guna lahan dengan menggunakan drone phantom 3 seri advance, berikut langkah - langkah teknik penggunaan drone :

1. SOP penggunaan drone

a) Melakukan pengecekan drone dan alat pendukungya dalam keadaan aman dan siap pakai

b) Memeriksa lingkungan, mencari sumber potensi gangguan seperti keramaian atau non fisik seperti gelombang radio atau elektromagnetik

c) Menentukan wilayah operasi penerbangan dengan pengamatan dan penggambaran lintasan

d) Kalibrasi penunjuk arah, kompas dan sensor lainnya jika ada

e) Setelah prosedur di atas terpenuhi, lakukan perekaman foto udara di wilayah yang menjadi target survey

\section{Penentuan Titik Acuan}

a) Berdasarkan kondisi operasional, lakukan penentuan titik koordinat awal menggunakan GPS sebagai acuan untuk mendapatkan titik koordinat lainnya. 
b) Lakukan perhitungan koordinat geografis terhadap titik-titik yang sudah ditentukan (per 25 meter) untuk mendapatkan koordinatnya dengan acuan titik koordinat awal yang sudah ditentukan.

3. Lakukan penggabungan data yang didapat dari peralatan drone berupa rekaman foto udara dan peralatan GPS berupa titik koordinat pada peta
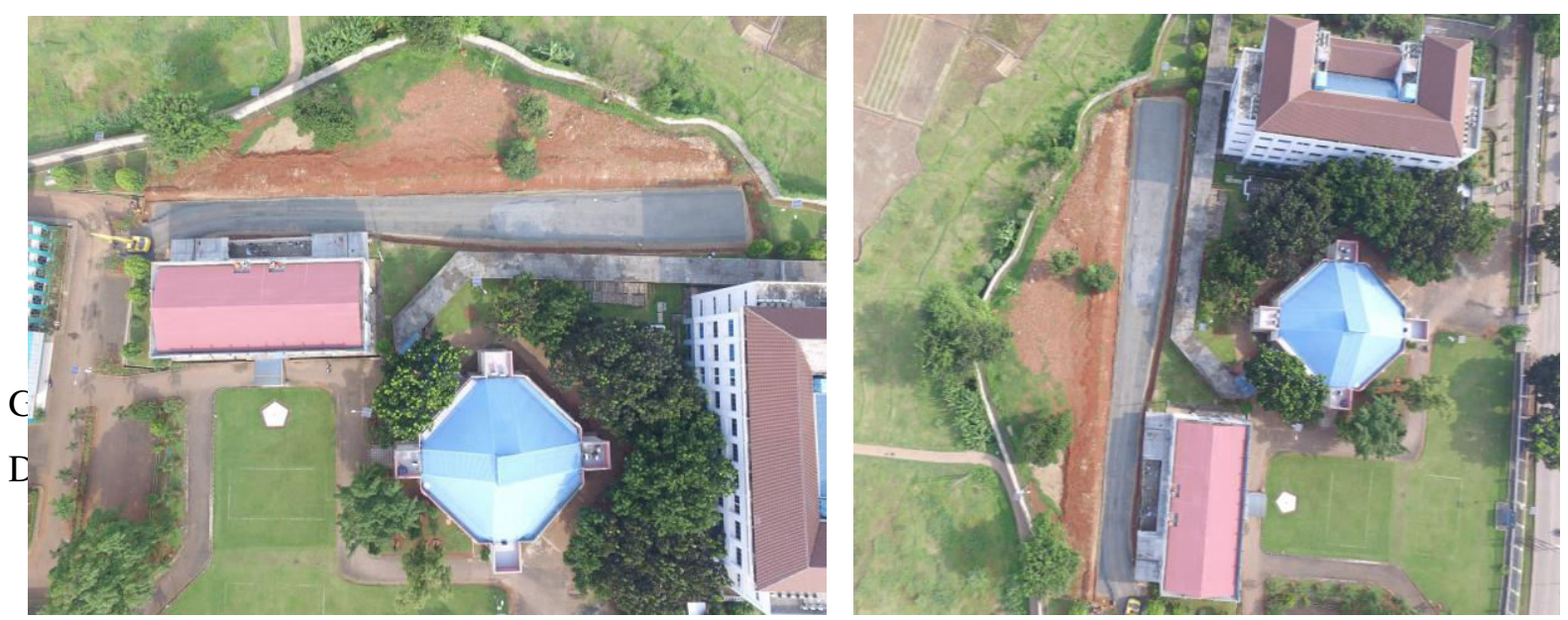

Dari hasil inventarisasi dengan menggunakan drone kita dapat mengetahui secara nyata bentuk lahan yang diinventarisasi dibandingkan inventarisasi secara manual overlay

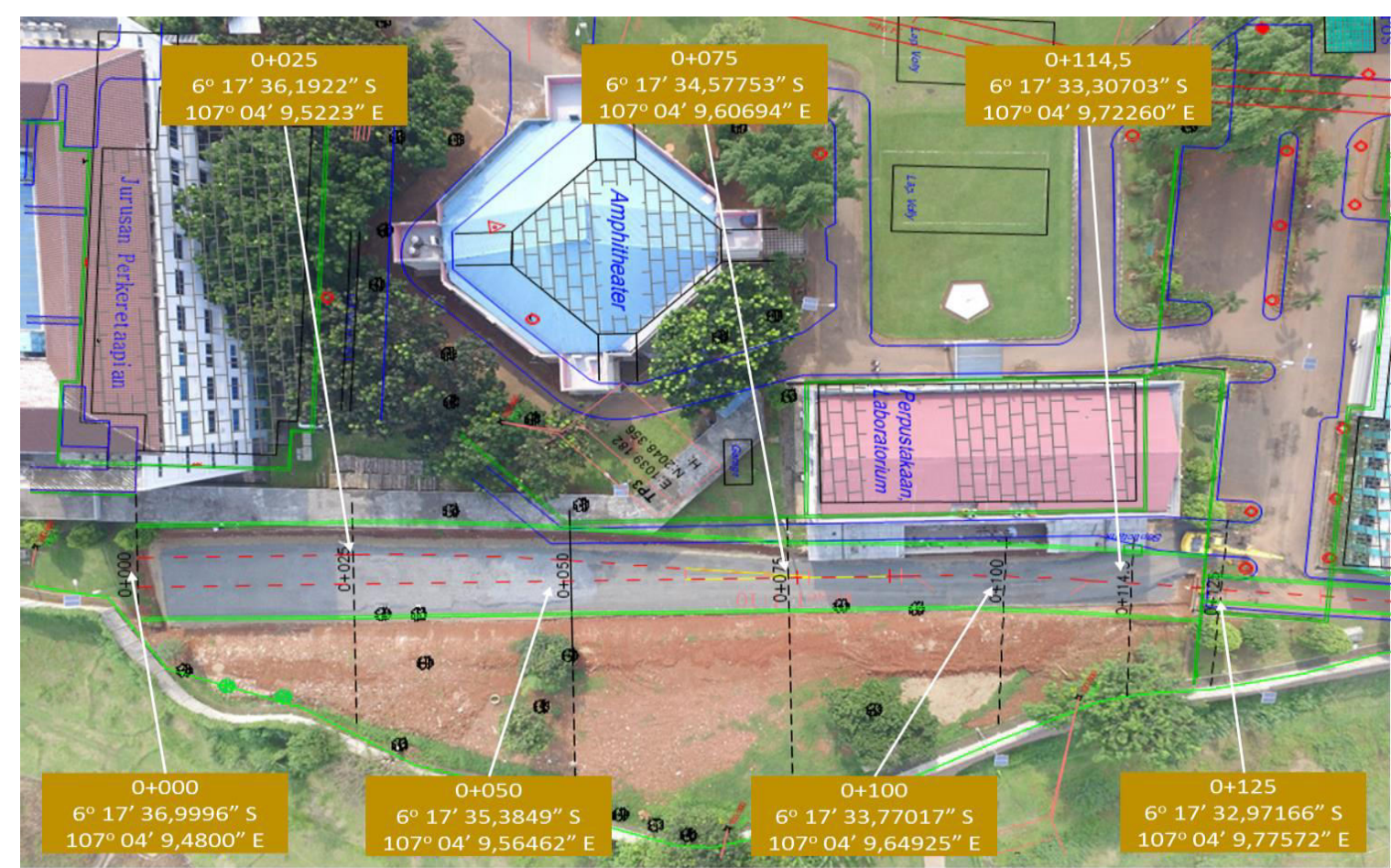

Gambar diatas merupakan gambar hasil overlay antara peta topografi dan hasil inventarisasi guna lahan dengan drone dimana dapat dilihat bahwa adanya kesejajaran dari hasil inventarisasi dengan peta topografi. Terjadi sedikit perbedaan titik 
dikarenakan pada saat inventarisasi dengan drone, pengambilan foto hanya 1 titik, dan dari jenis drone yang digunakan tidak memiliki sensor GPS sehingga tingkat keakuratan kurang maksimal

\section{KESIMPULAN DAN SARAN}

\section{A. KESIMPULAN}

1. Teknik inventarisai dengan drone jika kita mengambil gambar dari beberapa titik, maka akan didapatkan tingkat kesejajaran dengan peta semakin akurat, artinya penggunaan drone utk memiliki hasil yg akurat harus dilakukan perekaman lebih dr 1 titik terhadap wilayah yg di survey

2. Dapat diketahui bahwa lokasi pembangunan track KA antara peta topografi dan hasil perekaman drone menunjukkan kesesuaian titik yang sama.

\section{B. SARAN}

Dalam teknik inventarisasi dengan menggunakan drone

1. Drone yang digunakan minimal memiliki instrument (Kamera, GPS dan sensor kompas) agar keakuratan hasil foto dapat meningkat

2. Untuk inventarisasi lahan yang lebih luas dapat menggunakan drone dengan jenis sayap tetap. 


\section{DAFTAR PUSTAKA}

Undang-Undang Republik Indonesia No.2 Tahun 2012 Tentang Pengadaan Tanah Bagi Pembangunan Untuk Kepentingan Umum

Undang-Undang Republik Indonesia No.24 Tahun 1992 Tentang Penataan Ruang

Undang-Undang Republik Indonesia No.22 Tahun 1999 Tentang Pemerintah Daerah

Undang-Undang Republik Indonesia No. 5 Tahun 1960 Tentang Peraturan Dasar PokokPokok Agraria

Peraturan Pemerintah No 16 Tahun 2004 tentang Penatagunaan Tanah

Peraturan Pemerintah Nomor 69 Tahun 1996 tentang Pelaksanaan Hak dan Kewajiban, serta Bentuk dan Tata Cara Peran Serta Masyarakat dalam Penataan Ruang

Peraturan Pemerintah Nomor 36 Tahun 1998 tentang Penertiban dan Pendayagunaan Tanah Terlantar

Peraturan Pemerintah Nomor 25 Tahun 2000 tentang Kewenangan Pemerintah dan Kewenangan Provinsi Sebagai Daerah Otonom

Peraturan Pemerintah Nomor 20 Tahun 2001 tentang Pembinaan dan Pengawasan atas Penyelenggaraan Pemerintahan Daerah

Sutanto, 1986, Penginderaan Jauh, Jakarta

Tejoyuwono, 2006, Konsep Kegunaan Evaluasi dan Inventarisasi Harkat Sumberdaya mengenai Gatra Tanah, Universitas Gadjah Mada, Yogyakarta.

Shofiyanti Rizatus, 2011, Teknologi Pesawat tanpa awak untuk pemetaan dan pemantauan tanman dan lahan pertanian, Surabaya. 